\title{
The Difficulties of the Assessment of Tool Life in CNC Milling
}

\author{
Zinah J. Ahmed \\ Cardiff School of Engineering, Cardiff, UK, \\ Department of Mechanical Engineering, \\ Anbar University, Iraq \\ AhmedZJ@cardiff.ac.uk \\ Zinah_jummah@hotmail.com
}

\author{
Paul W. Prickett \\ Roger I. Grosvenor \\ Cardiff School of Engineering, Cardiff, UK \\ Pricett@cardiff.ac.uk \\ Grosvenor@cardiff.ac.uk
}

\begin{abstract}
In the manufacturing process, tool life is an important parameter in milling operations. The main objective of this paper is to explain how difficult is it to assess how much work a tool has undertaken before it must be changed. A number of ways of expressing tool life are currently used, including the conventional method based upon one of several configurations of the Taylor Tool Life Equation. These usually express tool life in terms of known material properties together with primary machining variables like speed, feed and depth of cut. Other approaches are based upon the extrapolation of a tool wear curve and considerations of the volume of metal removed. This initial investigation adopts an approach that is based upon a series of experiments, which produce data indicating the changes in machined feature form and dimension. For this study, a new test piece was designed in order to allow the indirect assessment of the tool flank wear by utilising a Coordinate Measuring Machine to accurately measure the workpieces. This work is intended to indicate how difficult it is to actually apply the existing methods to manage tool wear. The aim is to engineer a better way and to establish a methodology of measuring what the tool is actually doing in real time using the machine controller.
\end{abstract}

Keywords- tool life measurement; tool wear curve; metal removal rate.

\section{INTRODUCTION}

In many machining processes, the cutting tool is the least expensive component of the cutting system when compared to the machine and workpiece. However, a large element of process monitoring effort has concentrated on ensuring that the tool is in good working condition. This is because any damage to the cutting tool can result in catastrophic failure and cause severe damage to the machine and workpiece. This will also result in significant downtime and loss in productivity [1]. Amongst many reported approaches, Jawaid [2] investigated the influence of feed rate and cutting speed on tool performance under wet cutting conditions. Krain [3] considered the influence of operating parameters such as feed rate, radial depth of cut, tool material and geometry on tool life, tool wear and productivity obtained in end milling operations. Similarly, Filho [4] studied experimentally the influence of cutting parameters on tool life and surface finish. A novel method of measuring tool wear experimentally based on direct measurement the radius of a tool's cross-section using a Coordinate Measuring Machine (CMM) has been proposed [5].
In this paper, a different tool wear measuring methods have been used base on component features rather than by assessing the state of the cutting edge directly.

\section{TOOL LIFE MODELLING IN END MILLING}

\section{A. Taylor's Tool Life Equation}

The life of a cutting tool can be most simply defined in terms of the time interval for which the tool works satisfactorily. It is affected by many factors. These include cutting speed, feed rate, depth of cut, tool geometry, chip formation, the rigidity of the work holding and the utilized machine tool. In addition, it will be the affected by the physical and chemical properties of the workpiece material.

The earliest effective approach to determine tool life for a given cutting speed was proposed by Taylor 1906[6]. This approach suggested that, for progressive wear, the relationship between the time to tool failure for a given wear criterion and cutting speed was of the form:

$$
V \cdot T^{n}=C
$$

Where: $V$ is the cutting speed $(\mathrm{m} / \mathrm{min})$ and $T$ is the tool life. This is normally measured in the most relevant time base (minutes). In this simplest of forms the constants $n$ and $C$ are defined for the particular combination of tool and workpiece material combinations and other machining variables such as feed rate and depth of cut. Values for $n$ and $C$ can be obtained from standard tables for different workpiece materials and different cutting tools.

However, this equation does not include the effect cutting tool geometry, cutting feed, depth of cut and is limited to a certain range of speed [7]. Taylor's extended equation addresses this:

$$
V^{\frac{1}{n_{1}}} \frac{1}{f^{n_{2}}} d^{\frac{1}{n_{s}}} T=C
$$

Where the exponent $n_{1}, n_{2}$, and $n_{3}$ are constant and determined empirically. $f$ is the feed ( $\mathrm{mm} / \mathrm{rev}$.) and $\mathrm{d}$ is the depth of cut (mm). 
This equation gives a better opportunity for accurately considering the parameters affecting wear, but it can only be used to estimate tool life and does not relate directly to tool wear. It also requires a large amount of tests to establish the value of the coefficients. It should be noted also that there are many types of work materials and cutters used in industrial operations, meaning that developing an empirical tool wear model for each those is time-consuming.

\section{B. The Extrapolation of a Tool Wear}

The wear of the tool is produced by the contact and relative sliding between the cutting tool and the workpiece under the most extreme conditions that apply only to the actual cutting area. It is therefore very important and necessary predict tool wear in cutting operations in order to plan tool changes and avoid economic loses.

The methods of tool wear measurement can be broadly split in to two types, direct and indirect methods [8]. Direct measurements can be fast and accurate. Direct measurement entails measuring the actual wear, using different methods such as: optical measurement, radio-activation analysis and electrical resistance measurements. However, the direct measurement of tool wear between or during machining operations is difficult.

Indirect measurements may be online (or in process) and use machining process signals, such as cutting force, acoustic emission, sound, current power for various drives and vibration. These signals can be related to tool condition parameters that are known to be significantly affected by tool wear. There are other indirect measurements that are basically offline and relate to workpiece condition, including the measurement of the changes in machined component dimension or geometric form, the value of the volume of metal removed and component surface finish and/or roughness.

Tool wear is most often associated with flank wear land (VB) and widely used as a tool life criterion because it has adverse effects on the surface finish quality and the dimensional accuracy of the component. It is potentially simple to determine tool wear quantitatively, but this is not so in a practical context. It is normal practice to assert that a tool should be considered to have reached the end of its useful life when flank wear has been attained to result in a specified dimension. [9]. Fig.1 shows the general curves of flank wear and its relationship with tool life. The dynamic behavior of the tool wear curve is nonlinear at the initial stages, linear at intermediate stages and nonlinear at the final stages before the tool breaks completely. The initial stage is very fast, then it evens out to a more gradual pattern until the limit is reached; after that, the wear rate substantially increases. Despite the changes of the cutting conditions, the general shape of the flank wear curve stays the same.

It can be stated that these changes are affecting the tool life, i.e. the gradient of the curve, especially the linear section. Cutting speed, feed rate and depth of cut are the most important cutting parameters in relation to tool wear.

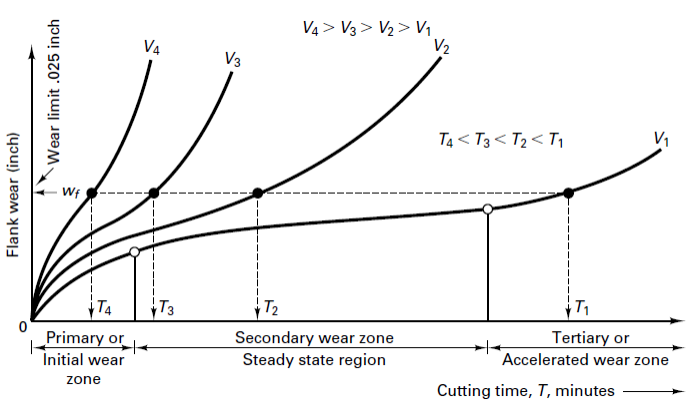

Fig. 1 General tool wear curves for flank wear at different velocities [10].

\section{Consideration of Metal Removal Rate}

Metal removal rate can be defined as the volume of metal removed per set time, such as mm3 per minute, "(3)". For simplicity, metal removal rate can also be defined based upon an "instantaneous" material removal rate defined as "the rate at which the cross-section area of material is being removed as the tool moves through the workpiece" [10] "(4)" and "(5)". The volume of metal, which is removed by a cutting tool, depends on the cutting speed, feed rate, depth of cut and time. In terms of constant cutting conditions, the progress of flank wear in the steady wear phase of the tool life curve (shown in Fig.1) is directly proportional to the actual machining time or the volume of metal removed. Under such constraints, this relationship can be used as a failure criterion for the tool wear and tool life.

The simpler direct basis for MMR considers the volume cut out of the workpiece and the time is taken for the material removal.

$$
Q=(\text { vol. }) /(\text { time of machining })
$$

Where: $Q$ is the metal removal rate $\left(\mathrm{cm}^{3} / \mathrm{min}\right)$ and vol. is the volume removed in $\mathrm{cm}^{3}$.

The formula for determining MRR remains the same although the milling strategies for removing material and the tools available have changed dramatically through the development of the modern CNC machine tool. This formula includes consideration of the depth of cut, the width of cut and the feed rate to find (cubic centimetres) per second or minute of material removed. This is typically calculated using:

$$
Q=\frac{a p * a e * v f}{1000}
$$

Where: $a p$ is axial depth of cut $(\mathrm{mm}), a e$ is radial depth of cut $(\mathrm{mm})$ and $v f$ is the table feed or feed rate $(\mathrm{mm} / \mathrm{min})$.

Note that "(4)" also can be written as:

$$
Q=\frac{a p * a e * f * n * N}{1000}
$$

Where: $f$ is the feed per tooth (mm/tooth), $n$ is the number of teeth and $N$ is spindle revolution speed per minute (rpm). 
MRR per unit time is inversely proportional to the cutting area of the tool, provided the other cutting condition constant.

\section{EXPERIMENT-BASED APPROACH TO TOOL LIFE ASSESSMENT}

The aim of the experiments performed within this initial work was to establish and verify the approach adopted to the feature measurement, which was designed to directly obtain the tool flank wear. In this work, the tool wear estimation method was developed based on component metrology. It has been established to enable the consideration of the effect of machining conditions on tool wear. The key idea the method is to employ the features of a milled hole to record the tool wear status. The proposed method is carried out post-process, meaning that it does not require the stopping of the machine tool and the removal of the component between operations. However, the removal of the finished component from the tool bed results in a loss of reference between tests and required the careful design and specification of key features which were deployed to provide continuity along each series of tests.

\section{A. Milling Machine}

The initial experimental work was performed on the Mazak Vertical Centre Smart 430A (MVCS) as seen in Fig. 2. The MVCS's ability to machine in three-axis enables the production of complex components and shapes. The maximum specified spindle speed is $12000 \mathrm{rpm}$, allowing for a broad range of cutting parameters. Another feature that made the MVCS a suitable machine was its capacity to hold multiple tools at once. As complete testing of tools could need more than one sitting, this allowed the cutting tool to be left on the machine without having to be removed and refitted by a technician, which could have potentially caused the tool to be positioned and set up differently, so affecting the results.

\section{B. Workpiece and Cutting tool Material}

In this study, a bright mild steel workpiece was milled using a high-speed steel $10 \mathrm{~mm}$ diameter 4-flute end mill cutter. Mild steel is a cold drawn low carbon steel that is often used in metal cutting processes, particularly milling.

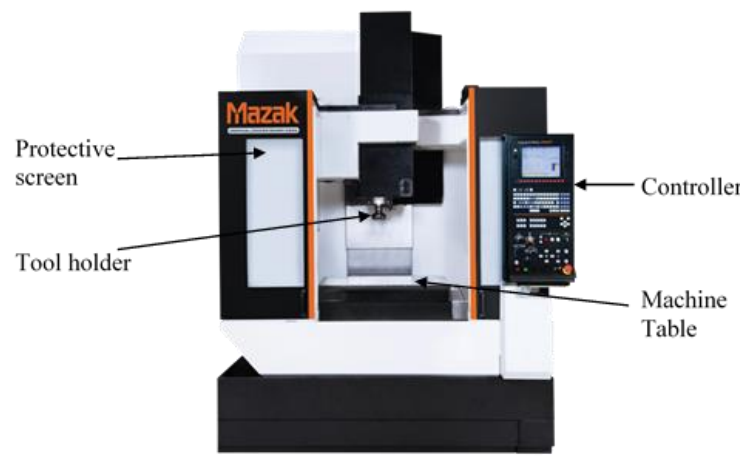

Fig. 2 Mazak Vertical Centre Smart 430A [11]

\section{Test Piece Setup}

Fig. 3 represents the CAD part drawing that was uploaded to the MVCS and the CMM. This sketch was done using Solidworks 3D CAD software. The dimensions of the test piece were $125 \times 220 \times 25 \mathrm{~mm}$. There are eight $40 \mathrm{~mm}$ diameter holes, numbered 1 to 8 .

\section{Coordinate Measure Machine CMM}

In this study, the dimension of the machined components was measured using a CMM. The design of the CMM consists of a probe attached to the vertical component which is attached perpendicularly to a bridge structure. This bridge structure is in turn attached perpendicularly to a large granite bed. Air bearings along each component allow for smooth independent movement along the $\mathrm{X}, \mathrm{Y}$ and $\mathrm{Z}$ directions. The stylus probe is mounted to a motorised indexing head which in turn is mounted to CMM structure as shown in fig. 4. As the CMM is so precise, the temperature can have an effect on its accuracy. To avoid this the room in which the CMM is located is temperature controlled, also the large granite bed has a high thermal mass to further ensure that changes in temperature will not affect any gathered results.

\section{E. Cutting Condition Setup}

The conditions for the initial tests were selected by taking the recommended cutting speed for a milling operation involving a high-speed steel cutter and bright mild steel workpiece found in machinist's handbooks. The range of cutting conditions chosen in this study are presented in Table 1. In the experiment design, the tool path length of each cut was used to derive the cutting time.

\section{F. Experimental procedure}

The following paragraphs describe the proposed tool wear measurement method based upon the assessment of the features and the surface metrology of the components.

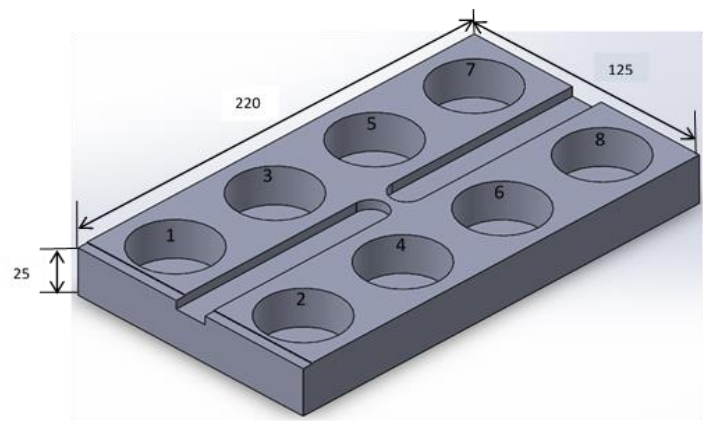

Fig. 3 CAD drawing of test piece

Table 1 machining parameters of verification experiment

\begin{tabular}{|c|c|c|c|c|c|}
\hline $\begin{array}{c}\text { Cutter } \\
\text { diameter } \\
(\mathbf{m m})\end{array}$ & $\begin{array}{c}\text { Spindle } \\
\text { speed } \\
(\mathbf{r p m})\end{array}$ & $\begin{array}{c}\text { Feed } \\
(\mathbf{p e r} \text { cut }) \\
(\mathbf{m m} / \mathbf{r e v})\end{array}$ & Feed rate & $\begin{array}{c}\text { Cutting } \\
\text { speed } \\
(\mathbf{m m} / \mathbf{m i n})\end{array}$ & $\begin{array}{c}\text { Tool } \\
\text { Path } \\
\text { Penin) } \\
\text { Length } \\
(\mathbf{m m})\end{array}$ \\
\hline 10 & 1656 & 0.17 & 281.5 & 52 & 129.968 \\
\hline
\end{tabular}




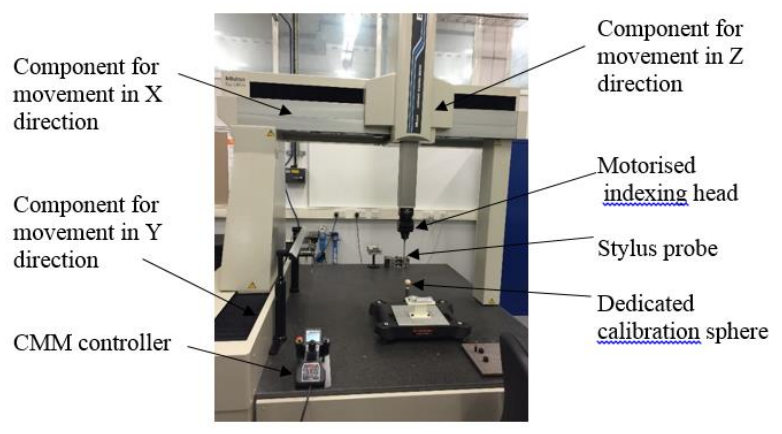

Fig. 4 CMM

Firstly, a brand new tool was fixed firmly in the tool holder of the machine. The tool had to be firmly tightened into the holder in order to prevent loosening which could lead to the tool moving in its holder and voiding results. Similarly, the prepared workpiece was fixed to the worktable of the machining centre using a standard vice. The CAD file was then uploaded to the $\mathrm{CNC}$ controller along with the information relating to the tool and workpiece materials and also cutting speed and depth. From this, the controller then set the optimum feed per cut and calculated the other cutting parameters. The controller also generated the cut path it would follow.

The tests were based upon milling a series of eight $40 \mathrm{~mm}$ diameter cylinders into a series of workpieces. The cutting operation for Cylinder one is explained in Fig. 5. In reality even a brand new tool does not have exactly the same cross section along its length, so on the basis that the material removed in machining Hole 1 Cylinder 1 was minimal, this hole was used to determine the initial tool diameter fig. 6 . This was then utilised as the reference diameter for the entire series. At the end of this process, each workpiece had been machined as shown in Fig. 3. Using three workpieces 24 holes were machined with constant cutting parameters.

\section{G. Tool Wear Measurement}

The method adopted was aimed at indirectly measuring flank wear of the major cutting edge of the tool based upon feature metrology by using CMM. Each of Cylinder was measured in two places at three points and an average diameter was established. After assessing the cylinder diameters of all the holes and calculating flank wear, it was possible to produce plots from which underlying trends could be determined.

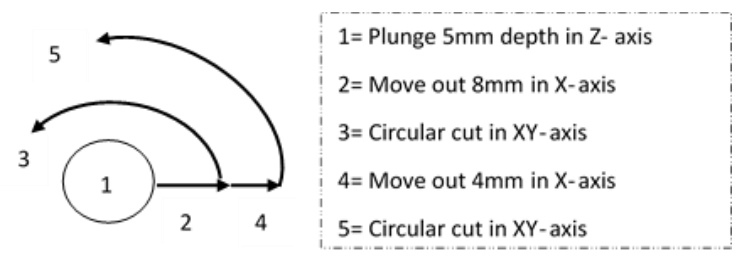

Fig. 5 Diagram of Cutting Operation for Each Cylinder

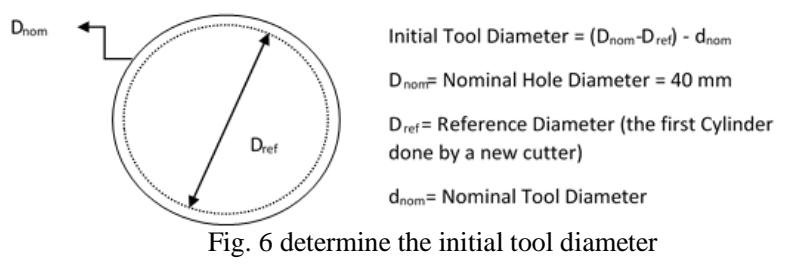

IV. RESUlTS AND DISCUSSION

\section{A. Tool Life Results and Discussion}

To apply Taylor's equation, it is usual for the cutting conditions to be kept constant, and for the workpiece and tool materials to be unaltered and the tool geometry unchanged, Even so, the values of $\mathrm{V}$ and $\mathrm{C}$ in "(1)" have been found to vary rather widely. This is due to the inherent variability in material properties from point to point on the same workpiece and in the tool and work materials from one batch to another. Moreover, factors such as machine vibrations, quantity, and the functions of the coolant supply may influence upon tool life [14].

This initial testing program was conducted using the simple Taylor tool life "(1)". This is based only upon cutting speed and is thus more normally used for turning operations. It does however; support the following explanation of the variability in tool life that can accompany the application of this type of assessment. The application of this method requires care as it is generic and must be adapted for each experimental setup. This is illustrated in Table 2, which summarises the difference between the Tool Life Equation as applied in different references. The major downfall with this approach is that tool life is dependent on more than just the material and machining; other factors include cutting tool material, cutting tool geometry, cutting mode, and machine condition.

Even this very simple assessment has shown that tool wear is a very complex problem and that this simple equation is not able to take into account all of the variables. It is also the case that the majority of tools being used in industry will not be used on a single task for their entire life, but will be used on a variety of different operations possibly with different materials, cutting speeds, cutting depths and feed rates. The attempt at including relevant parameters results in the extended considerations included in "(2)".

Under the scenario associated with "(1)", tools are replaced when this tool life is reached, regardless of the actual tool condition.

Table 2. The difference between calculated and experimental tool life.

\begin{tabular}{|c|c|c|c|c|}
\hline $\begin{array}{c}\text { Tool Life calculated using Tool } \\
\text { Life Equations from cited } \\
\text { references (in minutes) }\end{array}$ & \multicolumn{2}{|c|}{ Experimental work } \\
\hline$[10]$ & {$[12]$} & {$[13]$} & $\begin{array}{c}\text { Actual Time } \\
\text { Work (minutes) }\end{array}$ & $\begin{array}{c}\text { Cutter } \\
\text { Status }\end{array}$ \\
\hline 2.5 & $0.17-78$ & 10.78 & 46 & bad \\
\hline
\end{tabular}


However, in many cases, this means that tools are underutilised and downtime associated with the tool replacement process has been unnecessarily increased. This initial consideration suggests that the simple version of Taylor's equation "(1)" cannot give an accurate result because it has deficiencies in the tool life approach. In addition, it neglects other parameters such as depth of cut, feed rate, and tool geometry and workpiece hardness. However, the more complicated versions, such as "(2)", have little practical application. Additionally, Taylor's basic equation describes the linear section of the tool life curve and it is not possible to know the wear of the tool at any time $T$ during the machining. It is worthwhile mentioning that in the case of different cutting speeds, the time is not a good parameter for tool wear.

\section{B. Tool Wear Results and Discussion}

In this work, the depth of cut and feed per revolution were kept constant. Based on the present study, several important characteristics began to be identified and are summarised in the following consideration. It can be observed from fig.7 that tool wear increases gradually with the holes machined through the series. In addition, it can be reasoned that the tool wear increases with cutting time.

As identified in fig. 1, the overall shape of the tool wear curve remains constant despite the changes in the cutting conditions. However, these changes are affecting the gradient of the curve. In addition, it can be seen from the fig. 8 that the diameter of the holes at the same depth of the corresponding regions became smaller from $39.88 \mathrm{~mm}$ to $39.5 \mathrm{~mm}$ as the milling experiments went on.

\section{MRR Results and Discussion}

A series of experiments were conducted in order to the effect of MRR on the tool wear in to be studied. The experimental cutting conditions are presented in table 1 . To mill a $40 \mathrm{~mm}$ diameter cylinder by using a $10 \mathrm{~mm}$ diameter cutter in end milling process, a number of cycles have been used. These cycles are explained in fig. 9a through 9e, and the cycles for the experimental work are presented in table 3 .

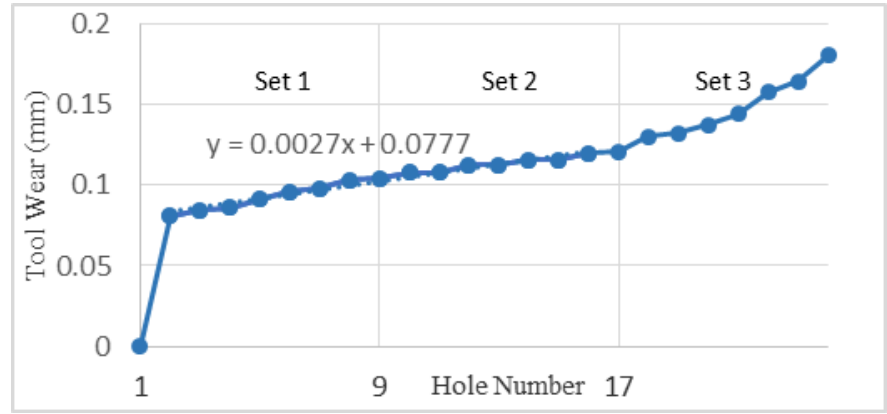

Fig.7 Tool Wear as a function of Hole Number

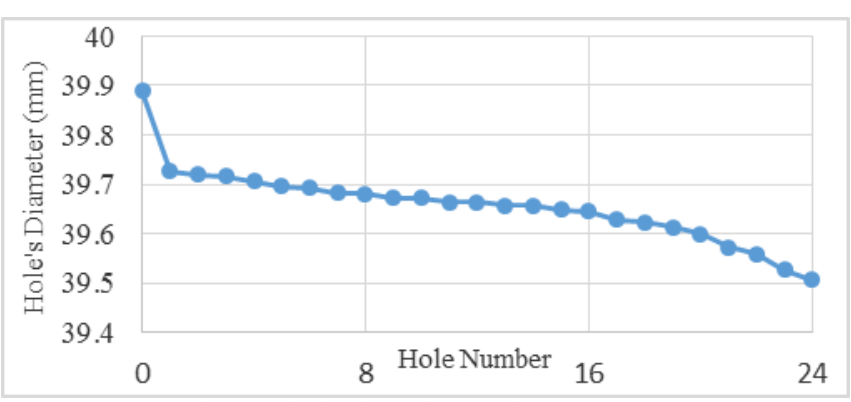

Fig.8 Variation in Cylinder Diameter

1-Plunge Milling $\quad \underline{2-\text { Move out } 8 \mathrm{~mm}}$
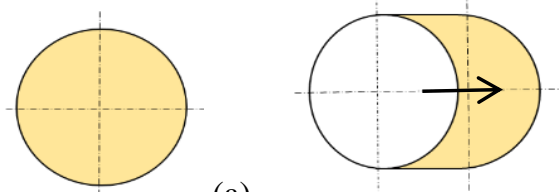

(a)

(b)

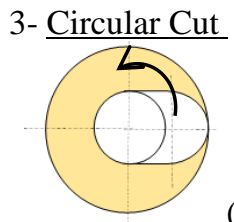

$\underline{4-\text { Move out } 4 \mathrm{~mm}}$

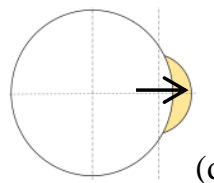

(d)

5- Circular cut

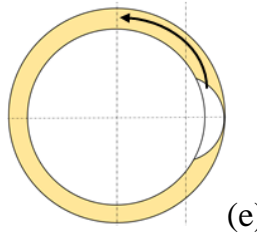

Fig.9 cutting cycles

Table (3) cutting cycles

\begin{tabular}{|l|l|l|l|}
\hline \multicolumn{2}{|c|}{ Operation } & $\begin{array}{l}\text { Time } \\
(\mathbf{s e c s})\end{array}$ & $\begin{array}{l}\text { Feed } \\
(\mathbf{m m} / \mathbf{r e v})\end{array}$ \\
\hline 1 & Plunge into workpiece (5mm depth) & 8 & 0.1 \\
\hline 2 & Move out by 8mm & \multirow{2}{*}{13} & 0.2 \\
\cline { 1 - 2 } 3 & Open out initial bore (circular cut) & & 0.2 \\
\hline 4 & Move to outer radius & 5 & 0.17 \\
\cline { 1 - 2 } 5 & Cut cylinder & 39 & $65 \mathrm{~s}$ \\
\cline { 1 - 1 } \multicolumn{2}{|l|}{ Total Time to machine cylinder } & \\
\hline
\end{tabular}

In this part, MRR has been calculated in three ways by using "(3)". Firstly, through the five phases shown in Figure 9 using the different machining processes the value calculated, called $\mathrm{Q} 1=17.5 \mathrm{~cm}^{3} / \mathrm{min}$. Secondly, based on the total time shown in table (3), the value calculated is $\mathrm{Q} 2=5.6 \mathrm{~cm}^{3} / \mathrm{min}$. Finally, based upon the total time, which derives from the tool path length of each cut given in the table (1), which called Q3 $=16$ $\mathrm{cm}^{3} / \mathrm{min}$. This, however, there is a difference in the results from this formula. The reason that Q1 is larger than Q2 and 
Q3 is because both Q2 and Q3 include some time when no cutting is being performed and neglects important changes in cutting operations, such as feed rate.

\section{CONCLUSIONS}

This approach makes it possible to draw a comparison to the differences between the basis used for the derivation of tool life using the different equations, "(1)" and "(2)". It has shown that "(1)" is not accurate and that "(2)" is too complicated for practical application.

In "(2)" and "(5)" much more specific cutting process information is utilised which, in both cases, may be difficult to acquire. This is illustrated in Table 2, which summarises the difference between the Tool Life Equation for this series from different references and the experimental results obtained. The work has also indicated however that the experimental based definition of metal removal rate is subject to variation, depending upon the calculation used. This suggests that the current method used for assessment is of little use in real terms as it is directly linked to this specific part process.

The conclusion must therefore be that much needed work is required, which is the aim of this on-going research. This will support these assessments but based upon more direct tool wear-related measurements acquired from the machine tool controller.

\section{REFERENCES}

[1] J. Gokulachandran and K. Mohandas "Application of Regression and Fuzzy Logic Method for Prediction of Tool Life" Procedia Engineering,38,pp.3900-3912,2012.

[2] A. Jawaid, S. Koksal, S. Sharif “ Cutting Performance and Wear Characteristics of PVD Coated and Uncoated Carbide Tools in Face Milling Inconel 718 Aerospace Alloy" Journal of Materials Processing Technology, 116,pp.2-9,2001.

[3] H. R. Krain, A. R. C. Sharman and K. Ridgway "Optimisation of Tool Life and Productivity when End Milling Inconel 718TM" Journal of Materials Processing Technology,189,pp.153-161,2007.

[4] Filho J. Caldeirani and Diniz A. E." Influence of Cutting Conditions on Tool Life, Tool Wear and Surface Finish in the Face Milling Process" Journal of the Brazilian Society of Mechanical Sciences, 24, 2002.

[5] X. Liu, C. Zhang, J. Fang and S. Guo, “ A New Method of Tool Wear Measurement" International Conference on Electrical and Control Engineering 2010.

[6] F. W. Taylor" On the art of Cutting Metal" 1906.

[7] B. Li " A review of tool wear estimation using theoretical analysis and numerical simulation technologies" International Journal of Refractory Metals and Hard Materials 35, pp. 143-151, 2012.

[8] Shao H., Wang H.L. and Zhao X.M. " A cutting power model for tool wear monitoring in milling” International Journal of Machine Tools and Manufacture 44, pp. 1503-1509, 2004.

[9] ISO 8688-2: 2011. Tool life testing in milling — Part 2: End milling. [Online]. Available at: https://www.iso.org/obp/ui/\#iso:std:iso:8688:2:ed-1:v1:en [Accessed: 11th February 2016].

[10] Black J. T." DeGarmo's Materials and Processes in Manufacturing" Hoboken, N.J.: J. Wiley. The United States of America. Tenth Edition 2007 .

[11] Mazakusa.com. 2016. VERTICAL CENTER SMART 430A. [online] Available at: https://www.mazakusa.com/machines/vertical-centersmart-430a/ [Accessed 26 Mar. 2016].
[12] B. L. Juneja and G. S. Skhon "Fundamentals of Metal Cutting and Machine Tools" New Delhi: New Age International. Second edition 2005.

[13] M. P. Groover" Fundamentals of Modern Manufacturing" Hoboken, N.J.: J. Wiley. The United States of America. Fourth Edition 2010

[14] J. Sun "Effect of Coolant Supply Methods and Cutting Conditions on Tool Life in End Milling Titanium Alloy" Machining Science and Technology 10, pp.355-370, 2006

Presented at:

The International Conference for Students on Applied Engineering, Newcastle, United Kingdom, 20-21 October 2016 